\title{
THE SHAPE OF FREE SPEECH: RE-THINKING LIBERAL FREE SPEECH THEORY
}

Anshuman A. Mondal, School of Literature, Drama and Creative Writing, University of East Anglia, Norwich, NR4 7RT, United Kingdom

Email: A.Mondal@uea.ac.uk; Tel: +44 (0)1603 597655

\begin{abstract}
:
Noting the apparent inconsistency in attitudes towards free speech with respect to antisemitism and Islamophobia in western liberal democracies, this essay works through the problem of inconsistency within liberal free speech theory, arguing that this symptomatically reveals an aporia that exposes the inability of liberal free speech theory to account for the ways in which free speech actually operates in liberal social orders. Liberal free speech theory conceptualizes liberty as smooth, continuous, homogeneous, indivisible, and extendable without interruption until it reaches the outer limits. This makes it difficult for liberal free speech theory to account for restrictions that lie within those outer limits, and therefore for the ways in which restraints, restrictions and closures are always-already at work within the lived experience of liberty, for it is these - and the inconsistencies they give rise to - that give freedom its particular texture and timbre in any given social and cultural context. The essay concludes with an alternative 'liquid' theory of free speech, which accounts for the 'shaping' of liberty by social forces, culture and institutional practices.
\end{abstract}

Keywords: free speech; freedom of expression; liberalism; John Stuart Mill; antisemitism; Islamophobia; liberty; liquidity 
In the spring and summer of 2016, the UK Labour Party was engulfed in controversy surrounding the tolerance or otherwise of antisemitism within its membership. The suspension of Naz Shah MP, then a parliamentary aide to the Shadow Chancellor for antisemitic postings on her Facebook page during the height of the Gaza crisis in 2014 - prior to her election as an MP - precipitated ongoing media coverage and the ensuing furore led the leader of the party, Jeremy Corbyn - someone well-known for his pro-Palestinian politics and longstanding criticisms of Israel's policies towards its Occupied Territories - to establish an independent enquiry and commission; in turn, the UK Parliament Home Affairs Select Committee also established a separate enquiry into the scope and extent of antisemitism within British political parties (Stewart 2016, Committee 2016). Both the extent of the controversy and the subsequent commissions of enquiry were a signal of the intolerability of antisemitism within British political and public discourse. This can be contrasted with the ways in which Islamophobia merits no such urgent attention; indeed, the former Conservative cabinet minister and now incisive and trenchant critic of government policy towards the UK's Muslim communities, Baronness Sayeeda Warsi, has gone so far as to suggest that Islamophobia is not only tolerable within British public and political life, it has become so normalized within both political and civil society that it has 'passed the dinner party test' (Batty 2011).

The question posed by this contrast between the intolerability of antisemitism and the tolerance, even normalization, of Islamophobia is why the former falls under the rubric of 'hate speech' and the latter does not; or, to put it another way, why the former is not protected by the rubric of freedom of expression, whilst the other does indeed appear to be. Indeed, the intolerability of expressions of antisemitic sentiment has been intensified by the UK government's recent adoption of the International Holocaust Remembrance Alliance's definition of antisemitism, which suggests that 'over-sweeping condemnation' of Israel would be a form of antisemitism, as would any criticisms of its policies as a state if those were conceived in relation to Israel as 'a Jewish collectivity' (Walker 2016). This potentially expands the legal proscriptions against expressions of antisemitic sentiment from 'hate speech' to certain forms of political criticism, not just of the state of Israel but Zionism as 
a political movement and ideology more generally, on the grounds that 'Zionism, at its core, is the belief based on the state of Israel to exist...connection to Israel is a key part of Jewish identity.' (Weisfeld 2016) It is this connection between Jewish identity and the state of Israel that potentially makes criticisms of Israel and Zionism antisemitic and therefore a form of hate speech that warrants no protection on the grounds of freedom of expression. On the other hand, Muslim protests against the ways in which the Prophet has been portrayed have consistently failed to muster any support on the grounds that restrictions on such portrayals would constitute an intolerable infringement of the right to free speech even though there is arguably a deeper connection between the Prophet and Muslim identity than that between Israel/Zionism and Jewish identity since the latter predated both the state of Israel and political Zionism, whereas the Prophet is the foundational figure of the Muslim faith: without him, there is no Muslim identity as such.

Whilst it is notable that many of the public figures, politicians and intellectual figures who vociferously supported the exposure of and clampdown on contemporary expressions of antisemitism also vociferously opposed Muslim arguments for protection from freedom of speech, my purpose in this essay will not be to explore any arguments concerning hypocrisy, cognitive dissonance, double-standards and so on, but rather to take this discrepancy as a point of departure for examining the question of inconsistency and discrepancy within contemporary and historical liberal theorizations of freedom of expression, insofar as these theorizations are the most dominant frames through which issues and controversies concerning freedom of expression are approached. This question is particularly pertinent because it compels us to critique liberal free speech theory, which, since its modern formulation by John Stuart Mill in On Liberty (1859), has been structured around a binary opposition between free expression and censorship that is precisely the reason why any inconsistency in the manifestation of liberty in actually existing liberal social orders is itself such a symptomatic aporia that generates confusion and anxiety among liberal free speech advocates and, most of all, stimulates an urgent compulsion on their part to straighten the crooked timber of liberty as and when they can. Through a symptomatic reading of this attitude towards inconsistency, 
I will argue that such an aporia in fact exposes the inability of liberal free speech theory to theorize adequately the ways in which free speech actually operates in liberal social orders. In turn, this illuminates the inadequacies of liberalism's theorization of freedom more generally, precisely because liberal thought is constituted by an opposition between freedom and power (which gathers under its rubric all the other antitheses to liberty such as tyranny, oppression, censorship and so on) that does not, in fact, hold and which leads, therefore, to an under-theorization of the ways in which power itself structures and shapes what is experienced as 'freedom'.

The antipathy towards inconsistency in liberal thought is registered in various tropes and styles of argument within liberal free speech discourse. "[O]ne of the weaknesses of free speech rhetoric," writes Simon Lee, "has been the tendency to stretch support all the way from political speech to pornographic expression, under the mistaken belief that arguments for one must apply to the other." (Lee 1990, 34) As I have noted elsewhere, this involves a logic of substitutability that renders context meaningless and superfluous, a logic that can trace its pedigree all the way back to Mill (Mondal 2014, 36). As Alan Haworth has noted, Mill rests his general arguments for freedom of expression on what Mill himself calls his 'prioritisation of thought and discussion,' which means that he (Mill) assumes that the case for 'that way of collectively striving for the truth and the case for other freedoms such as the "absolute liberty of expressing and publishing opinions" are equivalent.' (Haworth 1998, 27) In other words, the freedom appropriate to what Haworth calls 'the seminar room' is, by extension, applicable to all other contexts until it reaches the point where liberty may legitimately be curtailed; conversely, any disturbance or discontinuity of this smooth extensibility is deemed an inappropriate infringement of liberty. In order to extend the continuity of liberty on which his argument rests to the greatest possible extent, Mill is compelled to extend it as far as possible, to the outer limits where the law may legitimately intervene (in his case, the famous example of direct incitement of a mob standing outside a corn dealer's house). 
Mill thus introduces into modern liberal free speech theory a notion of liberty that exists as if on a single plane: smooth, continuous, homogeneous, indivisible, and extendable without interruption until it reaches the outer limits. The dominant governing metaphor here is that of the horizon, the point beyond which freedom no longer obtains - hence the binary opposition between freedom of expression and censorship. The nature of freedom is unidimensional, reducible to the single aspect of its reach, its extension. From this perspective only the outer limits signify as legitimate restraints upon liberty; every restriction or regulation within these limits are aberrations because there can and should not be any irregularity, distortion, heterogeneity, discontinuity or inconsistency. This is why the 'slippery slope' argument plays such an important role in liberal free speech advocacy, for its rhetorical function is to keep the horizon at bay, to raise the spectre that its encroachment signals a dimunition of liberty across the board precisely because the logic of smooth, planar continuity necessitates that any encroachment at one point signals an encroachment at all points - visually speaking, one might see it as the conjuring of a circle being narrowed. It is telling, moreover, that the trope works by introducing an element of verticality (the slope) that upsets what should otherwise be a smooth, horizontal plane.

In liberal free speech theory - and indeed, in liberal theory generally - freedom is defined by the outer limits in quantitative terms as 'scope' and 'extent', which are terms that feature regularly in liberal discourses on freedom of expression. Qualitative discussions of liberty, including ethical questions about the moral rights and wrongs of exercizing one's freedom of expression, insofar as they feature at all, appear in liberal arguments only as an adjunct or corollary to the quantitative need to expand the reach of freedom as far as possible. Thus, for example, whilst Mill does indeed talk about positive liberty, by far the greater emphasis in On Liberty is on negative liberty. Indeed, his 'very simple principle' that is the foundation of his entire argument is a conception of liberty that is negative: 'The object of this Essay is to assert one very simple principle...that the sole end for which mankind are warranted, individually or collectively, in interfering with the liberty of action of any of their number is self-protection. That the only purpose for which power can be rightfully exercized 
over any member of a civilized community, against his will, is to prevent harm' (Mill 1859 [2011], 14). Tellingly, when Mill does discuss positive liberty, he calls it 'development' rather liberty, and he tends to position it as exterior to liberty itself, '[t]hese are cases in which the reasons against interference do not turn upon the principle of liberty: the question is not about restraining the actions of individuals but helping them...These are not questions of liberty, and are connected with that subject only by remote tendencies; but they are questions of development.' (Mill, 122-23) For Mill, liberty involves establishing the conditions in which it is possible for individuals to pursue as many 'experiments in living' as possible so as to contribute to the progressive development of humankind; each individual's capacity for development can and should be nurtured, but this principally involves leaving them alone as far as possible to get on with it. The positive liberty to which Mill turns as the justification of his argument for liberty thereby rests on a predicate, the negative liberty that enables the conditions in which it can develop and flourish. More recently, Mill's typically nineteenth century moral register has been eschewed by liberal discourse on free expression, which has adopted a strictly legalistic approach that concerns itself with where the horizon line curtailing the right to freedom of expression should be drawn, leaving aside all the ethical questions germane to the exercize of one's freedom as what might be termed a 'moral remainder' (Mondal 2014, 3). Such an approach, by definition, emphasizes negative liberty and is grounded more in the anti-consequentialist liberal tradition that emerged precisely in order to address some of the weaknesses of Mill's consequentialist, utilitarian approach (Rawls 2005). However, in grounding free speech in the discourse of 'natural' rights so as to avoid Mill's consequentialism, this tradition of liberal thought in fact accentuates and intensifies Mill's 'planar' model because it is even more rigidly binary in terms of the constitutive distinction between freedom and its other, and therefore stronger in its emphasis on negative liberty: as a natural right, freedom of expression can only be limited by other rights. Without the back-up, as it were, of consequentialism's 'goal' or 'purpose', which might justify limits on free expression within the horizon of liberty, any restrictions that do appear within that horizon as part of everyday lived 
experience become all the more magnified as an intolerable incursion into the empire of liberty. This may be why contemporary free speech advocates, especially the more absolutist of them, draw so heavily on anti-consequentialist arguments in their rhetoric even as they simultaneously (and contradictorily) deploy Millian arguments as well (Mondal 2014). ${ }^{1}$

This emphasis on negative liberty, then, both generates and is of a piece with the binarism that is so typical of liberal thought. Liberal conceptions of freedom work in terms of a binary between freedom and its other, be it oppression, suppression, censorship, regulation and so on, these antithetical terms being generally substitutable. Again, one can turn to Mill as the exemplar if not the source of this structure of thinking within modern liberalism. On Liberty draws a series of sharp distinctions in order to scaffold its argument, the principal one being that between an autonomous and sovereign individual, on the one hand, and society (often figured pejoratively as a 'mass') on the other. As Alan Ryan notes, even other liberals have found Mill's arguments in On Liberty to be 'excessively individualistic,' but although many of them may have softened the edges of the opposition, they have always upheld it since the sovereign individual is at the core of liberalism: it makes it what it is (Ryan, 'Introduction' in Mill 1859 [2011], xxii). Much depends on the difference between what Mill calls 'the external relations of the individual' and 'all that portion of a person's life which affects only himself' (Mill 1859 [2011], 18). From this opposition Mill proposes that the latter is 'the appropriate region of human liberty [which] comprises, first, the inward domain of consciousness; demanding liberty of conscience, in the most comprehensive sense; liberty of thought and feeling; absolute freedom of opinion and sentiment on all subjects, practical or speculative, scientific, moral, or theological.' (ibid., my emphasis) He then goes on to suggest that '[t]he liberty of expressing and publishing opinions may seem to fall under a different principle, since it belongs to that part of the conduct of an individual which concerns other people; but, being almost of as much importance as the liberty of thought itself, and resting in great part on the same reasons, is practically inseparable from it.' It is worth dwelling at some length on this because, having established an opposition between 'that portion of a person's life which affects only himself' and 
'the external relations of the individual,' he then goes on to suggest that with regard to liberty of conscience and the liberty to express and publish opinions this distinction does not in fact hold, that the latter is in fact 'practically inseparable' from the former even though it 'may seem to under a different principle, since it belongs to that part of the conduct of an individual which concerns other people'. This auto-deconstruction of the fundamental premises of his argument is highly significant and has profound implications on how we might conceptualize not just freedom of expression, but also freedom more generally and the question of the individual/subject in relation to them, which I will discuss in due course. But for now it suffices that we should note that with respect to freedom of expression Mill's sleight of hand enables him to transfer that which is properly internal to the individual to the world of external relations and thereby endow upon that latter world - of expressing and publishing opinions - all the properties of the former. That is, it enables Mill to extend the 'absolute' freedom of opinion, which is proper to the interiority of individual conscience, to the external world of publishing and expression, and thereby continue that extension along the singular plane of liberty so conceived right out to the outer limits.

It is precisely because the external world of publishing and expression should mirror, by extension, the internal world of the conscience - the autonomous mind which should be allowed to entertain 'all subjects' - that Mill's arguments for 'liberty of thought and discussion' in the second chapter of On Liberty turn on the opposition between openness and closure. Since the absolute sovereignty of the conscience is carried over into the external world of expressing and publishing opinions, Mill argues that the 'lists' should be kept perpetually 'open' (28) so that any individual can access any and all possible ideas even though this does, in fact, stand in tension with his other argument that freedom of expression is necessary in order to enable the 'truth' to be ascertained (comprising his famous 'infallibility', 'testing' and 'partiality' arguments). His martial metaphors - e.g. 'both teachers and learners go to sleep at their post, as soon as there is no enemy in the field' (50) - when used as a vehicle for this epistemological argument, would suggest that the truth vanquishes falsehood. But if this is the case, then the trope of infinite and perpetual openness to all possible ideas must, by the 
very process of arriving at the truth, involve a form of closure that Mill would otherwise suggest is an intolerable infringement of liberty. He thus admits that '[w]rong opinions and practices gradually yield to fact and argument,' and that,

As mankind improve [sic], the number of doctrines which are no longer disputed or doubted will be constantly on the increase: and the well-being of mankind may almost be measured by the number and gravity of the truths which have reached the point of being uncontested. The cessation, on one question after another, of serious controversy, is one of the necessary incidents of the consolidation of opinion; a consolidation as salutary in the case of true opinions, as it is dangerous and noxious when the opinions are erroneous.

Perhaps realizing, however, what the implications are for his insistence on infinite and perpetual openness, he then goes on to suggest that:

though this gradual narrowing of the bounds of diversity of opinion is necessary in both senses of the term, being at once inevitable and indispensable, we are not therefore obliged to conclude that all its consequences must be beneficial. The loss of so important an aid to the intelligent and living apprehension of a truth, as is afforded by the necessity of explaining it to, or defending it against, opponents, though not sufficient to outweigh, is no trifling drawback from, the benefit of its universal recognition. Where this advantage can no longer be had, I confess I should like to see the teachers of mankind endeavouring to provide a substitute for it; some contrivance for making the difficulties of the question as present to the learner's consciousness, as if they were pressed upon him by a dissentient champion, eager for his conversion. (51) 
Having so vigorously argued that the reason freedom of expression is necessary is to enable the truth to emerge, Mill is here confronted with the implacable implications of that logic in the form of an admission that if freedom of expression is a means to an end (truth), that end will itself restrict the very freedom he argues is required to get there. He is forced, then, to invent a rather lame artificial simulacrum of freedom ("some contrivance") concocted by the 'teachers of mankind' in order to sustain that which is, on the one hand, absolutely necessary to human 'development' but is, on the other, oriented eventually toward the cessation of both 'development' and the need for freedom. Against this, Mill is forced to assert that the lists should somehow be kept open even though it is at odds with his argument about truth in order to keep at bay the auto-deconstructive implications, namely that the logic of closure secretly inhabits the fabric of freedom because it is not its antithesis or its 'other' but its necessary supplement, on which the concept of freedom depends. In the next section of this essay, I will attempt to show how this supplementarity is at work in 'free' societies but for now it is worth re-stating that if, in the course of both his argument that establishes the premises of liberty and the subsequent discussion of applications and practical consequences, Mill is compelled to blur the lines of the sharp distinctions he draws in order to establish his 'very simple principle', those distinctions are nevertheless the structural foundations of his view of liberty and this bequeaths to subsequent liberal thought a note of regret concerning any exceptions that might necessarily arise in the translation of liberal theory into lived experience. Even the most pragmatic of liberals see restraints on freedom as a regrettable but unavoidable necessity, thus suggesting that restraint (or closure) is inimical to freedom and antithetical to it. While many contemporary thinkers writing within the broad liberal tradition have addressed liberal free speech theory's limitations with respect to hate speech with some, like Jeremy Waldron and the critical race theorists, demonstrating that Mill's 'harm principle' extends to forms of speech beyond direct incitement (Waldron 2012, Matsuda et al. 1993), and others addressing the tension that consequently arises between liberty and equality (Levin 2010, Saunders 2011), I would suggest that we should go further and deconstruct the constitutive oppositions of liberalism in order to attend to 
the restraints, restrictions and closures that are always-already at work within the lived experience of liberty, for it is these - and the inconsistencies they give rise to - that give freedom its particular texture and timbre in any given social and cultural context.

\section{II}

In contrast to the liberal conception of freedom as 'planar' and unidimensional, I would like to amplify and substantiate Talal Asad's intuition that social forces, culture and institutional practices 'shape' freedom, and especially freedom of expression, in particular, context-specific and historically determined ways (Asad 2011, 6763 [Kindle]). Rather than visualizing freedom in terms of its scope and extent, across a flat and uniform social space that is emptied of context, I suggest we conceptualize liberty in terms of forces and flows channelled by and through an irregular and uneven terrain. From this perspective, as regards freedom of expression in particular, discourse can be conceptualized as elemental, as 'liquid'; it will follow whatever channels it can and fill the available space. ${ }^{2}$ The freedom of discourse, then, is not one of being or not being free, of having or not having free speech. In so far as discourse is plastic, malleable, freedom of discourse is channelled, shaped, sculpted, and, like flows of liquid, may in turn channel and sculpt. Some of the forces that shape free speech are dense, have great mass and, like the earth itself, are only slowly and incremetantally modified: these are the great institutional bulwarks - law, the state, the bureaucratic machinery; others are like shoals of sand, as much shaped by as shaping the currents: civil society, culture, ideology, moral norms and values. The social terrain within which liberty is lived is, then, something like that represented by an ordnance survey map marked by contours indicating gradients and degrees of resistance and obstruction.

If we were to illustrate the ways in which this conception of free expression is at work in actually existing free societies, we might first point to the institutional landmarks that mark the terrain 
through which it flows, in particular the legal statutes and provisions through which the power of the state to shape freedom is enforced. In relation to the discrepancy with which I began this essay, one might point to the ways in which the flow of antisemitic expression is intensely obstructed by the incitement to racial hatred provisions of the Public Order Act 1986, which encompasses 'racialised' religious groups such as Sikhs and Jews but does not cover other religious groups such as Muslims, Hindus and Christians, although the UK's blasphemy laws would have performed an adjacent function with respect to Christians until their abolition in 2008. In contrast, although the Racial and Religious Hatred Act 2006 (RRHA) was framed as an extension of the protection against incitement to hatred enjoyed by Jews and Sikhs to other religious groups, its passage into law was itself shaped by cultural and ideological forces that took great pains to ensure that the extensive protections afforded racialized groups against hate speech in the 1986 Public Order Act were not carried over into the new Act (Mondal 2014, 185-192). These attentuating forces both accepted the existing bulwarks on free expression - by, for example, accepting the need for limitations on freedom of expression with regard to certain classes of hate speech - but mobilized on behalf of particular conceptions of 'free speech' in order to ensure that the terrain of free expression was not altered so as to materially obstruct free expression with respect to other, non-racialised religious identities. Consequently, the Racial and Religious Hatred Act 2006 was effectively rendered a 'dead letter'. This partially explains, then, the inconsistency in the UK with regards to antisemitic and Islamophobic expression, but it must be borne in mind that this is itself part of a wider terrain shaping free expression in the UK, which includes legal statutes that restrict expression with regard to the right to protest; copyright; the restriction of access to forms of expression based on age; the prohibition of certain forms of expression because of their exploitation and abuse of other persons; laws on libel, slander, privacy and so on. All these legal provisions constitute a jagged patchwork of restrictions and restraints that channel speech and expression, with varying degrees of intensity and force.

However, such legal landmarks are but one dimension of the ways in which expression is shaped. As the above example of the RRHA demonstrates, if the terrain through which expression flows is 
sculpted and shaped by ideological and cultural forces that are themselves articulated by forms of expression that are channeled by and through it, then the lie of the land, so to speak, is itself complexly determined by the dialectic between what is expressed and the limits to expression. If the Public Order and Racial and Religious Hatred Acts constitute two particular legal landmarks which channel understandings of permissible and impermissible speech with respect to religious identity, then these are themselves shaped by cultural and ideological framings of 'religion' 'race' and identity. As Nasar Meer (2008) has noted, wider understandings about religion and race as 'voluntary' and 'involuntary' identities, respectively, are at work within contemporary British society, and I have argued at length elsewhere how these wider understandings fed into the specific debates that surrounded the introduction of the RRHA in ways that decisively shaped and attenuated the form in which it eventually arrived onto the statute books (Mondal 2014, 186-188). Beyond these are more general ideological configurations impalpably and imperceptibly shaping, for example, perceptions and prejudices pertaining to particular religious identities such as Muslims and Jews. Liberal free speech theory finds it acutely difficult to account for the ways in which culture and ideology predetermine the shape and flow of free expression principally because, following Mill, there is an aversion to closure. Moreover, there is little recognition of the ways in which closure that is, the ways in which all possible ideas are not always and perpetually available to any given individual - relates to foreclosure, those predetermined and pre-inscribed limits not just to expression but also thought. This is principally because, on the one hand, liberal theory's reliance on the sovereign individual relies on an abjuring of any substantive theory of subjectivity as, for example, has developed in various nonliberal accounts such as Marxism, psychoanalysis, structuralism and post-structuralism; and, on the other, because the individual's sovereignty would be inevitably and always-already compromised by any theory that presupposes not only that this individual's autonomy is not a pre-given axiom but, in fact, is impossible. 
Mill does, in fact, come close to acknowledging something akin to a theory of hegemony; indeed, it is paradoxically central to the argument of On Liberty, as is evident in the above quotation about 'the truths which have reached the point of being uncontested' being the consequence of an 'inevitable and indispensable' process. His principal concern is not with political tyranny, as such, although, like every liberal he is of course opposed it; rather, in On Liberty, he is more concerned with the 'moral coercion' exerted by society on individuals to conform to certain expected norms of thought and behavior. It is on the grounds of resisting this social pressure that he makes his case for liberty of conscience, of thought and expression, and of pursuing one's own course in life as long as one does not harm or interfere with the life and liberty of others. At times, he explicitly suggests that the effect of this is to foreclose what might be thought or even perceived by any given individual: 'In our times,' he writes, 'from the highest class of society down to the lowest, every one lives as under the eye of a hostile and dreaded censorship...I do not mean that they choose what is customary, in preference to what suits their own inclination. It does not occur to them to have any inclination, except for what is customary.' (Mill 1859 [2011], 70, my emphasis) This seems to be very closely aligned to a Gramscian theory of hegemony, but if this is the effect of social coercion, such that an individual appears to consent to their own oppression, then this not only undermines the individual's autonomy of thought, but also forecloses any possibility of thinking otherwise: '[a]nd thus is kept up a state of things very satisfactory to some minds, because, without the unpleasant process of fining or imprisoning anybody, it maintains all prevailing opinions outwardly undisturbed' (39). Again Mill here threatens to undermine his own argument, so he is compelled to state that '[o]ur merely social intolerance kills no one, roots out no opinions, but induces men to disguise them, or to abstain from any active effort for their diffusion.' (ibid.) If social coercion 'roots out no opinions' then this suggests that in the minds of men all possibilities are always infinitely open, but the effect of the coercion is simply to keep a lid on the expression of them. This notion of closure is more congenial to Mill than the implied foreclosure he admits elsewhere because, as we have seen, one of the structuring oppositions upholding his argument is the one between openness and 
closure; foreclosure, on the other hand, undercuts this opposition and compromises the autonomy of the individual. If the individual is not autonomous, if what $s /$ he thinks is not a matter of rational choice, but an effect of power, of structural relations in society, of unconscious and irrational motivations then s/he is not and cannot possibly be the 'sole author' (Smith 2012) of themselves and of what they say: they are, instead, subject to pressures external to themselves - thereby undercutting the basis of Mill's 'very simple principle'.

It is, for this reason, that Mill turns Marxian conceptions of power and ideology on their head: Mill is concerned with the social 'tyranny' of the majority over an embattled minority, whereas the Marxian tradition is concerned with the ways in which ideology enables and sustains the hegemony of a minority over a majority. This minoritarian emphasis in Mill is a strand of liberal thought that resonates particularly strongly in contemporary free speech advocates who portray themselves as an embattled minority defending Enlightenment rationalism (and, sotto voce, male white privilege) from the tyranny of 'political correctness'. And just as Mill's pressing need to quarantine the rationally autonomous and sovereign individual from social tyranny blinded him to the pressure of structural forces he is elsewhere forced to admit but nonetheless keep at bay, so too does contemporary liberal thought continue to find difficulty in accounting for the effect of power relations and structural forces, nowhere more so than in the circulation and flow of ideas, opinions, and forms of discourse. 'All the political changes of the age promote [social conformism and mass mediocrity]' writes Mill in chapter two of On Liberty

since they all tend to raise the low and to lower the high. Every extension of education promotes it, because education brings people under common influences, and gives them access to the general stock of facts and sentiments. Improvements in the means of communication promote it, by bringing the inhabitants of distant places into personal contact, and keeping up a rapid flow of changes of residence between one place and 
another. The increase of commerce and manufactures promotes it, by diffusing more widely the advantages of easy circumstances, and opening all objects of ambition, even the highest, to general competition, whereby the desire of rising becomes no longer the character of a particular class, but of all classes. A more powerful agency than even all these, in bringing about a general similarity among mankind, is the complete establishment, in this and other free countries, of the ascendancy of public opinion in the State...[which ensures] there ceases to be any social support for nonconformity any...protection [of] opinions and tendencies at variance with those of the public. (83)

It is difficult to see how under conditions of such extensive material pressure it could ever be possible for the 'diversity of opinion' that gives rise to individuality to remain perpetually and infinitely open, especially given that he concludes here by saying the the greatest effect of such material pressure is on the conformism of 'public opinion' and its effect on government. What Mill is doing here is what he does elsewhere too: gesturing beyond closure towards an understanding of foreclosure not merely as an effect of political suppression or even psychological coercion but as something that materially structures 'free' societies.

\section{III}

There is also another way in which freedom of expression is channeled and shaped by social forces, and this is by what I have elsewhere termed the 'politics of free speech' (Mondal 2014). This politics is, of course, most visible during public controversies over free speech itself, but by far the most significant way in which the politics of free speech shapes and channels the flow of social discourse and circulation of ideas is through what might be termed a vernacular politics of free speech, which encompasses the everyday regulation and negotiation, on the one hand, of speech codes in the 
workplace and other public spaces, all of which intersect with legal, institutional, cultural and ideological frameworks; and, on the other hand, the more informal testing and contesting of the limits of speech proprieties in various other social spaces. Moreover, the modalities of such politics can encompass both the singular and discrete acts of particular individuals and the public mobilization of groups and organizations within civil society - and any position in between.

Take, for example, the circulation of knowledge in institutions of learning such as schools and universities. Debates and disputes about curriculum and canon selection (the two are, of course, intimately related) are not often framed in terms of freedom of expression; on the other hand, it has long been acknowledged that there are deeply political concerns at work in the selection of a curriculum and the formation of a pedagogic or cultural canon, including questions about power, authority and exclusion. These inevitably intersect with and impinge upon the flow of discourse, but perhaps one reason concerns about freedom of expression are seldom raised is because most people accept that there needs to be some kind of closure in any curriculum, that not everything can be taught within it, and therefore a process of selection and exclusion must inevitably take place. As a result, in most discussions and debates about curricula the politics of knowledge rarely intersects with the politics of free speech because these debates are rarely - if ever - framed in terms of censorship, and they are rarely framed in terms of censorship because the censorship remains largely invisible - although, as I shall argue, whether to even call it censorship is problematic. When the politics of free speech involved in the practice, policy and policing of education does become visible, such questions are raised, but they are broached in such ways as to invite further examination of the inadequacy of prevailing conceptions of free speech in accounting for them.

In the US, the adoption of public (that is, state) school textbooks, and therefore the content and structure of the curriculum has long been the arena for political contest action between liberals and conservatives (Taylor 2017). Christian pressure concerning the content of school textbooks in the United States can be traced back to the mid-nineteenth century, but it is only since the advent of the 
Civil Rights and Women's Movements from the 1960s - and the subsequent 'New Right' reaction on behalf of Christian fundamentalist groups - that the politics of education has become a prominent and highly visible frontline in the 'culture wars' (Taylor, 13-16). The existing research literature on these efforts to shape the textbooks being procured on behalf of schools in the US, which is largely conducted from within a liberal paradigm, does frame them in terms of 'censorship' but it does so either solely in relation to conservative efforts - thereby assuming that 'liberal' or 'progressive' efforts to shape the curriculum do not warrant consideration under the censorship rubric - or they dismiss both liberal and conservative efforts from the Olympian height of an idealist commitment to infinite and perpetual openness, 'treating both as irksome distractions from the true purpose of education.' (Taylor, 26) Either way, an opposition is set up between openness and closure and this in turn enables the construction of a subsequent opposition between liberal shaping as 'inclusive' and conservative efforts as 'exclusionary'. While the latter is aligned with 'censorship' the former is identified as 'selection':

While censorship involves approaching literature with the intent of weeding out what is objectionable, selection involves approaching literature with the intent of finding that which is most excellent. Censorship seeks to exclude where selection seeks to include; selection prioritizes the right of the reader to read, while censorship prioritizes the protection of the reader from the presumed effects of reading. (Taylor, 7)

Taylor notes, however, that 'humanist' pressure on publishers and school boards in the wake of the Civil Rights and Women's movements initially proceeded with regards to 'the eradication of racist and sexist language' as well as the 'inclusion of material by and about racial minorities and women in the curriculum.' (28) This being the case, it is clear that the opposition set up by liberal observers of this particular form of politics between conservative 'censorship' and liberal 'selection'/inclusion 
(with its connotations of openness) does not entirely hold. This is evident in the terminology employed to characterize the process, which ranges from "pre-publication censorship" to "proactive censorship" to "silent editing" (6). The last term in particular illuminates the extent to which any sharp distinctions cannot be sustained for the adjective is clearly redundant - all editing is silent and invisible unless specifically flagged up in order to draw attention to itself (as in scholarly editions) and the term's emergence as a 'byproduct' of James J. Lynch and Bertrand Evans' survey of literature anthologies, grammar and composition books, during which they discovered that 'pages were removed and works were cut to fit the available space' (24) merely underscores the point: all editors wrestle with these considerations on a daily basis; this does not make them censors because censorship is not the appropriate term to be applied here.

Thus, while Taylor is right to suggest that 'content analysis' of textbooks that have been subject to 'expurgation' may reveal the 'internal logic of the censoring bodies more clearly than does an examination of straightforward banning. While the removal of an entire book from the curriculum...sends a clear message as to the intolerability of the views it expresses, it is not clear what aspects of the book are most intolerable,' while 'line-by-line comparison of an expurgated text with its source text illuminates exactly which words in which contexts and combinations are fund objectionable' (21) - and she does this to great effect in her own analysis - the point I am making is that this is only the visible tip of a very large iceberg which, in these instances, can with some justification and rigorous analysis be aligned with 'censorship' but which, in most cases, cannot because the line between editing and expurgation is not as clear as liberal theories of free speech and censorship would have us believe. Indeed, the same lack of distinction is also operative with respect to 'selection'. The 'removal' of a work may be due to censorship but there are other reasons why works might be removed from the curriculum, reasons which undercut the alignment of 'removal' with 'censorship' and, conversely, 'selection' with 'inclusion'. Firstly, since curricula are limited in all sorts of ways - by time, principally - the idea that 'selection' can be simply a 'broadening of the scope of material presented to students' (28) such that 'inclusion' does not have 
to be accompanied by an accompanying 'exclusion' is a fallacy that speaks to the liberal trope of infinite and perpetual openness. Second, any removal of a text may not, in fact, be tantamount to a great act of excision but rather a pragmatic decision based on the suitability of that particular text to the learning criteria and outcomes of that particular curriculum. These can intersect with all sorts of other material factors that bear down on the selection and deselection of learning materials, as anyone with pedagogic experience will know. And behind all this, informing and shaping all these factors, are moral considerations with respect to the instructors' relation to the material he or she is teaching. This is clearly part of the textbook adoption scenarios Taylor and others have examined, but they are equally germane to individual tutors who make morally informed personal choices as to what to present to their students; to align these moral choices with 'censorship' is to reduce the complexity of syllabus formation into the 'flat' and one-dimensional consideration of liberty that I have discussed above: in some cases it is, indeed, appropriate to talk of the effect of these choices in terms of 'censorship' but, conceptually speaking, it is not possible to draw a sharp distinction between them and these other considerations - ultimately, at a conceptual level, the question of whether what has not been adopted has therefore been 'banned' or 'prohibited' is a tricky one that is in fact undecidable in advance. The same is perhaps less true of texts that have been expurgated, where the term censorship might indeed be appropriate; but expurgation is also an extreme form of editing, and there is a continuum in the editing process whereby some forms of editing may be more indistinct and where the term 'censorship' might be too clear-cut a term to be really precise.

There are further considerations that need to be accounted for here, all of which shape freedom of discourse at a vernacular level, and on an everyday basis, in ways that cannot be encompassed by the sharp distinction of freedom and censorship. Principal among these are the commercial and economic factors that are largely invisible but which have a profoundly important effect on the kinds of discourse that is made available in the 'marketplace of ideas,' to use a key liberal metaphor. One of the great advantages of examining textbook adoption processes - and here Taylor's research is exemplary - is the way in which it reveals the extent to which commercial considerations decisively 
shape the terrain of discourse in free societies. In the United States, the school textbook marketplace is unlike a 'normal' market insofar as it is more akin to government procurement conducted by 'elected officials who need to satisfy their constituents in order to retain their positions' - hence the politicization of the process (Taylor, 16). In these conditions, 'publishers must go to great expense to develop new series of texts without any guarantee that they will be approved...It is therefore in the publishers' interests to produce material that will be considered non-controversial by the widest range of readers' (16-17). The result is that publishers produce 'complex lists of content guidelines to assist book editors in their attempt to toe the narrow line' between what liberal and conservative protestors deem acceptable (16). As a result, the flow of discourse is profoundly shaped by rather mechanistic accommodations and negotiations that are, ultimately, as much rooted in mundane - banal, even - considerations of profit and loss as the moral sensitivities of the respective political antagonists. While these particular circumstances are peculiar to the United States, the wider point is generalizable to other societies.

\section{IV}

What I have tried to do in this essay is to outline the ways in which the shaping of freedom, and of freedom of expression in particular, both constitutes and is constituted by the dynamic of hegemony and counter-hegemony, the shifting of closures and foreclosures that define the limits of freedom within and without the bounds of the law in liberal social orders. The multidimensionality of this complex process stands in stark contrast to the 'planar' model of liberty that operates within liberal free speech theory. Shifting the terms of debate on freedom of expression within liberal social orders is such an urgent and vital task, then, because the dominant ways in which it is conceptualized are all rooted in the liberal free speech tradition, which does not accord with and is inadequate to account for how freedom of expression actually works as a lived practice as opposed to an abstract theoretical principle. Moreover, liberal free speech theory is itself not logically 
consistent even when it tries to suggest that consistency is precisely what freedom requires. This, in turn, is rooted in a structure of thinking that conceptualizes freedom in terms of its antithesis, and freedom of expression in terms of the opposition between openness and closure. If, on the other hand, I have insisted on dismantling these oppositions it is because they simply cannot be sustained either theoretically or in relation to social life. We will never grasp what freedom is if we continue to view it only by the shadow cast by tyranny, by the other which alone gives freedom its form and substance in many liberal imaginings. We need instead to see it as a complex and subtle web of relations, subject to pressures and forces that not only provide the context for liberty as a lived practice but its content as well. In short, liberty is the sum of a whole series of calibrations and compromises, such that to speak disparagingly and regretfully of one's freedom being 'compromised' is to spectacularly misunderstand the very nature of freedom itself.

\section{REFERENCES}

Asad, Talal. 2011. "Freedom of speech and religious limitations." Rethinking secularism:282-297.

Batty, David. 2011. "Lady Warsi claims Islamophobia is now socially acceptable in Britain." The Guardian, 20 January. https://www.theguardian.com/uk/2011/jan/20/lady-warsiislamophobia-muslims-prejudice.

Bauman, Z. 2013. Liquid Modernity: Wiley.

Calhoun, C., M. Juergensmeyer, and J. VanAntwerpen. 2011. Rethinking Secularism. Kindle edition ed: Oxford University Press.

Committee, Home Affairs. 2016. Antisemitism in the UK. London: UK Parliament.

Haworth, Alan. 1998. Free speech. London: Routledge.

Lee, Simon. 1990. The cost of free speech: London : Faber, 1990. Non-fiction.

Levin, Abigail. 2010. The cost of free speech : pornography, hate speech and their challenge to liberalism. Basingstoke: Palgrave Macmillan.

Matsuda, M.J., C.R. Lawrence, R. Delgado, K.W. Crenshaw, and C. R. 1993. Words That Wound: Critical Race Theory, Assaultive Speech, And The First Amendment: Avalon Publishing.

Meer, Nasar. 2008. "The politics of voluntary and involuntary identities: Are Muslims in Britain an ethnic, racial or religious minority?" Patterns of Prejudice 42 (1):61-81. doi: 10.1080/00313220701805901.

Mill, John S. 1859 [2011]. "On Liberty." In: Kindle edition.

Mondal, Anshuman A. 2014. Islam and controversy : the politics of free speech after Rushdie. Basingstoke: Palgrave.

Rawls, John. 2005. A theory of justice: Cambridge, Mass. ; London : Belknap Press of Harvard University Press.

Saunders, K.W. 2011. Degradation: What the History of Obscenity Tells Us about Hate Speech: NYU Press. 
Smith, Zadie. 2012. NW: London ; New York : Hamish Hamilton, 2012.

Exclusive signed ed. Novels.

Stewart, Heather. 2016. "Naz Shah suspended by Labour Party amid antiseitism row." The Guardian, 27 April. https://www.theguardian.com/politics/2016/apr/27/naz-shah-suspended-labourparty-antisemitism-row.

Taylor, Sara. 2017. "We Don't Need No Education: Belief, and The Expurgation of US Public School Literature Texts in Response to Activist Beliefs." PhD, School of Literature, Drama and Creative Writing, University of East Anglia.

Waldron, Jeremy. 2012. The harm in hate speech: Cambridge, Mass. : Harvard University Press, 2012. Bibliographies

Non-fiction.

Walker, Peter. 2016. "UK adopts antisemitism definition to combat hate crime against Jews." The Guardian, 12 December. https://www.theguardian.com/society/2016/dec/12/antisemitismdefinition-government-combat-hate-crime-jews-israel?CMP=Share iOSApp Other.

Weaver, Simon. 2011. "Liquid racism and the ambiguity of Ali G." European Journal of Cultural Studies 14 (3):249.

Weisfeld, Hannah. 2016. "What hope the fight against antisemitism when Malia Bouattia leads the NUS?" The Guardian, 22 April.

https://www.theguardian.com/commentisfree/2016/apr/22/antisemitism-malia-bouattianus-muslim-anti-zionist.

Werbner, Pnina. 2013. "Folk devils and racist imaginaries in a global prism: Islamophobia and antiSemitism in the twenty-first century." Ethnic \& Racial Studies 36 (3):450-467. doi: 10.1080/01419870.2013.734384.

\footnotetext{
${ }^{1}$ Indeed, with respect to free speech, the divergence between Mill and anticonsequentalism may not, in fact, be as great as it might at first appear. It could be argued that anti-consequentialist liberal arguments take issue not so much with Mill's theorization of free speech but his wider arguments for liberty. That is, in pushing his case to the 'outer limits' within which free speech should be virtually unlimited, Mill presses his argument for free speech - but not liberty per se - as far towards an anti-consequentialist position as his wider consequentialism will allow, such that liberal anti-consequentialism could be read as an attempt to address (and close) the gap between Mill's theorization of free speech and his more avowedly utilitarian arguments for liberty in general.

2 I echo here Zygmunt Bauman's work on liquid modernity and also work on liquid racism (Bauman 2013, Weaver 2011, Werbner 2013).
} 